\title{
Turbulence vertical structure of the boundary layer during the afternoon transition
}

\author{
C. Darbieu ${ }^{1}$, F. Lohou ${ }^{1}$, M. Lothon ${ }^{1}$, J. Vilà-Guerau de Arellano ${ }^{2}$, F. Couvreux ${ }^{3}$, P. Durand ${ }^{1}$, D. Pino ${ }^{4,5}$, E. G. Patton ${ }^{6}$, \\ E. Nilsson ${ }^{1,7}$, E. Blay-Carreras ${ }^{4}$, and B. Gioli ${ }^{8}$ \\ ${ }^{1}$ Laboratoire d'Aérologie, Toulouse, CNRS UMR 5560, Université de Toulouse, Toulouse, France \\ ${ }^{2}$ Meteorology and Air Quality Section, Wageningen University, Wageningen, the Netherlands \\ ${ }^{3}$ CNRM-GAME (Météo-France and CNRS), Toulouse, France \\ ${ }^{4}$ Department of Applied Physics, Universitat Politècnica de Catalunya, BarcelonaTech, Barcelona, Spain \\ ${ }^{5}$ Institute of Space Studies of Catalonia (IEEC-UPC), Barcelona, Spain \\ ${ }^{6}$ National Center for Atmospheric Research, Boulder, Colorado, USA \\ ${ }^{7}$ Uppsala University, Uppsala, Sweden \\ ${ }^{8}$ Institute of Biometeorology, National Research Council (IBIMET-CNR), Florence, Italy
}

Correspondence to: C. Darbieu (darc@aero.obs-mip.fr)

Received: 7 November 2014 - Published in Atmos. Chem. Phys. Discuss.: 22 December 2014

Revised: 24 July 2015 - Accepted: 24 July 2015 - Published: 9 September 2015

\begin{abstract}
We investigate the decay of planetary boundary layer (PBL) turbulence in the afternoon, from the time the surface buoyancy flux starts to decrease until sunset. Dense observations of mean and turbulent parameters were acquired during the Boundary Layer Late Afternoon and Sunset Turbulence (BLLAST) field experiment by several meteorological surface stations, sounding balloons, radars, lidars and two aircraft during the afternoon transition. We analysed a case study based on some of these observations and largeeddy simulation (LES) data focusing on the turbulent vertical structure throughout the afternoon transition.

The decay of turbulence is quantified through the temporal and vertical evolution of (1) the turbulence kinetic energy (TKE), (2) the characteristic length scales of turbulence and (3) the shape of the turbulence spectra. A spectral analysis of LES data, airborne and surface measurements is performed in order to characterize the variation in the turbulent decay with height and study the distribution of turbulence over eddy size.

This study highlights the LES ability to reproduce the turbulence evolution throughout the afternoon. LESs and observations agree that the afternoon transition can be divided in two phases: (1) a first phase during which the TKE decays at a low rate, with no significant change in turbulence characteristics, and (2) a second phase characterized by a larger
\end{abstract}

TKE decay rate and a change in spectral shape, implying an evolution of eddy size distribution and energy cascade from low to high wave number.

The changes observed either in TKE decay (during the first phase) or in the vertical wind spectra shape (during the second phase of the afternoon transition) occur first in the upper region of the PBL. The higher within the PBL, the stronger the spectra shape changes.

\section{Introduction}

The transition from a well-mixed convective boundary layer to a residual layer overlying a stable nocturnal layer raises several issues (Lothon et al., 2014), which remain difficult to address from both modelling and observational perspectives. The well-mixed convective boundary layer with fully developed turbulence is mainly forced by buoyancy. The afternoon decrease in the surface buoyancy flux leads to the decay of the turbulence kinetic energy (TKE) and a change in the structure of the turbulence, which shows more anisotropy and intermittency. It is important to better understand the processes involved, as they can influence the dispersion of tracers in the atmosphere (e.g. Vilà-Guerau de Arellano et al., 2004; Casso-Torralba et al., 2008; Carvalho et al., 2010; 
Taylor et al., 2014) and the development of the nocturnal and daytime boundary layers of the following days (BlayCarreras et al., 2014b).

Turbulence decay has been studied with laboratory experiments (e.g. Monin and Yaglom, 1975; Cole and Fernando, 1998), theoretical models (Goulart et al., 2003), numerical studies with large-eddy simulations (LESs) (e.g. Nieuwstadt and Brost, 1986; Sorbjan, 1997; Rizza et al., 2013a) and observations (e.g. Fitzjarrald et al., 2004; Grant, 1997; Brazel et al., 2005; Fernando et al., 2004). In all of these studies, the decay was mainly related to the decrease in the surface buoyancy flux but with complexity gained with shear-driven boundary layers (Pino et al., 2006; Goulart et al., 2010), which slow the decay. Using LESs, Nieuwstadt and Brost (1986) considered a sudden shut-off of surface heat flux and found that turbulence decay occurred within a period of the order of the convective timescale $t_{*}=z_{i} / w_{*}$, where $z_{i}$ is the planetary boundary layer (PBL) depth and $w_{*}$ is the convective velocity scale (Deardorff, 1970). However, different results were obtained if a slower decrease in the forcing surface buoyancy flux is considered with an external timescale $\tau_{\mathrm{f}}$ (Sorbjan, 1997; Rizza et al., 2013a, b; Nadeau et al., 2011). If $\tau_{\mathrm{f}}$ is large relative to $t_{*}$, the turbulence can adjust to the forcing change, in quasi-equilibrium, as noted by Cole and Fernando (1998). This is the case in the mid-afternoon PBL, when $t_{*}$ is around 10 or $15 \mathrm{~min}$ and $\tau_{\mathrm{f}}$ is around 2 or $3 \mathrm{~h}$. Sorbjan (1997) found that the TKE decay scales with $\tau_{\mathrm{f}} / t_{*}$, with $t_{*}$ estimated at the start of the decay. But in late afternoon and around sunset, $t_{*}$ starts to increase significantly (until the definition of $w_{*}$ becomes questionable at zero buoyancy flux), and turbulence may not be able to adjust to the external change. Consequently, an extensive description of the turbulence structure is needed to better understand this decay process in the PBL.

The evolution of the turbulence length scales across the afternoon transition has not been addressed extensively, but several studies can be found that show diverging results. Considering eddy lifetime, or the "turn over" timescale, one may state that smaller eddies will decay earlier than larger eddies (Davidson, 2004). This is one explanation given by Sorbjan (1997), from an LES study, for the increase in the characteristic length scale of the vertical velocity found in the mixed (then residual) layer of the LES. In the surface layer, one may expect the length scales to decrease, as inferred by Kaimal et al. (1972) from the study of surface-layer spectra evolution with stability during the Kansas experiment. On the basis of tethered-balloon observations, Grant (1997) showed that the peak of the vertical velocity spectrum shifts to smaller length scales in the surface layer during the evening transition. Finally, Nieuwstadt and Brost (1986) and Pino et al. (2006) found that the length scale of the maximum spectral energy of the vertical velocity remained constant during the decay process. By using a theoretical model of the TKE spectrum and LES, Goulart et al. (2010) have also found that the spectral peak remains at approximatively the same wavelength when shear is strong enough to prevent the spectral peak of vertical velocity from shifting towards shorter wavelengths. For other meteorological variables, such as the horizontal wind components, temperature and moisture, Pino et al. (2006) have shown that the characteristic length scales increase with time.

The evolution of the turbulence scales remains unclear and only partly understood. It must be thoroughly investigated whether the scales in the mixed, and afterward residual, layer really increase or not. Considering the time response and equilibrium aspect mentioned above, and the possible decoupling with height between the stabilizing surface layer and the overlying residual layer, it is also important to consider the vertical structure of turbulence decay, i.e. the evolution of turbulence and scales as a function of height. Except for Goulart et al. (2010), the numerical studies quoted above (e.g. Sorbjan, 1997; Pino et al., 2006) considered TKE to be integrated over the entire PBL depth, and observations of the turbulence decay were, most of the time, made at surface (Nadeau et al., 2011). Only a few observational studies considered the vertical structure of the turbulence's afternoon decay (Grant, 1997; Fitzjarrald et al., 2004, on the afternoondecaying PBL).

Here we investigate the evolution of the turbulence spectra and scales from surface to PBL top during the afternoon transition (AT) based on the BLLAST (Boundary Layer Late Afternoon and Sunset Turbulence) data set, collected during the summer of 2011 (Lothon et al., 2014). A cloud-free, weakwind day (20 June 2011) is considered in order to analyse the evolution of the turbulence, from midday to sunset, by using both observations and an LES model. Our analysis aims at (1) evaluating, with a complete observation data set, the ability of the LES to simulate the turbulence structure of the afternoon decay and (2) analysing the evolution of integral scales, TKE and the shape of the spectra in both observations and numerical simulation and as a function of height.

The article is organized as follows: in the next section, we present the experimental data set and describe the case study of 20 June 2011 through the observations (Sect. 2). In Sect. 3, the LES is presented and evaluated with the observations. Our spectral analysis method, used in both observations and LES, is then described in Sect. 4, before we present and discuss our results (Sect. 5). Concluding remarks are made in Sect. 6 .

\section{Experimental data set and case study}

The BLLAST experiment took place in the south of France, near the Pyrénées mountain range, during the summer of 2011. A set of various observational platforms (aircraft, remotely piloted aircraft systems, balloons) and continuous measurements (towers, remote sensing) monitored the PBL diurnal evolution, focusing on the AT, in various meteorological regimes. The BLLAST experiment provides a unique 
data set to investigate the vertical structure of the decaying PBL (see Lothon et al., 2014, for a detailed description of BLLAST objectives and the experiment).

The experimental data set used in this study, the case study chosen and its simulation are now described. Note that the site longitude is around $0.21^{\circ} \mathrm{E}$; consequently, UTC, very similar to local solar time, is used hereafter as the time reference.

\subsection{Experimental data set}

In order to monitor the evolution of the mean structure of the PBL during the AT (and initialize the simulation), we used standard radiosoundings launched every $6 \mathrm{~h}$, from 06:00 to 18:00 UTC, and hourly radiosoundings (Legain et al., 2013) of the lower troposphere (up to 3 to $4 \mathrm{~km}$ ), from 13:00 to 18:00 UTC. The launching sites of the two types of radiosoundings were $4 \mathrm{~km}$ apart. The radiosondes measured temperature, water vapour content and the sonde location from which the horizontal wind components were deduced.

Surface energy balance and turbulence structure in the surface layer were provided by several ground stations over different vegetation coverages (wheat, corn, grass, pine forest and moor (composed of heather and gorse)). A permanent $60 \mathrm{~m}$ tower provided integrated turbulence measurements in the surface layer above the heterogeneous surface. The statistical moments were estimated over detrended 30 min periods from $10 \mathrm{~Hz}$ raw measurements. The surface heat fluxes are used as surface forcing in the simulation.

Two aircraft, the French Piper Aztec (PA) from SAFIRE (Service des Avions Français Instruments pour la Recherche en Environnement) (Saïd et al., 2005) and the Italian Sky Arrow (SA) from Ibimet (Istituto di Biometeorologia del CNR) and Isafom (Istituto per i Sistemi Agricoli e Forestali del Mediterraneo) (Gioli et al., 2006), carried out flights throughout a wide area during the afternoon, at 65 and $40 \mathrm{~m} \mathrm{~s}^{-1}$, respectively. They measured temperature, moisture, pressure, $\mathrm{CO}_{2}$ mixing ratio and $3-\mathrm{D}$ wind at $50 \mathrm{~Hz}(\mathrm{SA})$ and $25 \mathrm{~Hz}$ (PA) on 25 to $40 \mathrm{~km}$ legs stabilized in attitude and altitude. The detailed instrumentation of both aircraft is given in Lothon et al. (2014).

\subsection{Case description}

On the basis of meteorological criteria and data coverage, 20 June 2011 was selected as our case study. The synoptic situation was a high-pressure system over the southwest of France, with a light westerly wind leading to fair and cloudfree weather.

Figure 1 shows the normalized altitude $z / z_{i}$ of the stacked legs flown by the aircraft as well as the different launching times of the radiosoundings (the method used for the PBL height $\left(z_{i}\right)$ estimation is discussed later). The two aircraft flew simultaneously, the PA flying above the SA. They flew along west-east parallel legs, at three latitudes and, as shown

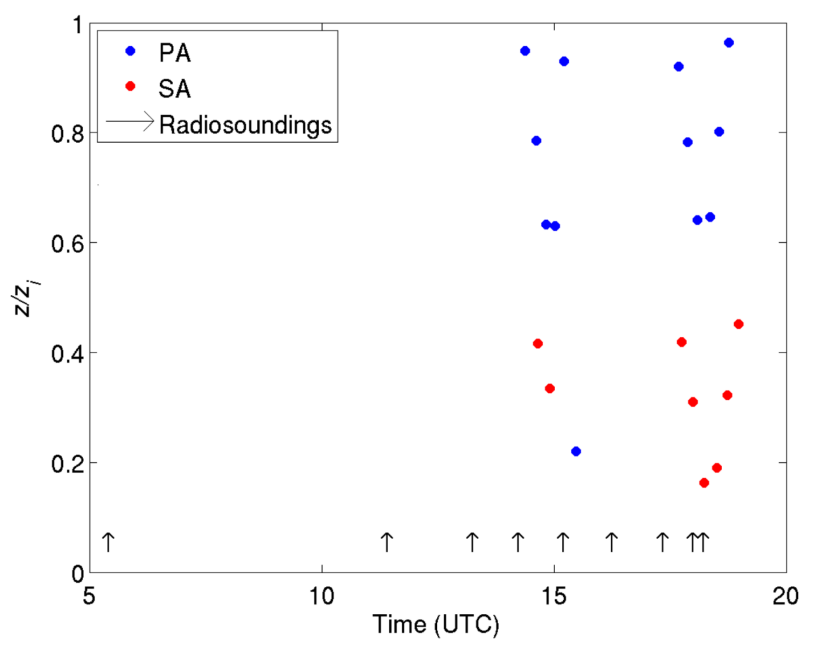

Figure 1. Normalized altitude $z / z_{i}$ (where $z_{i}$ is the PBL depth) of the legs flown by the two aircraft on 20 June 2011 (Piper Aztec in blue, Sky Arrow in red) and launching times of the radiosoundings (black arrows).

in Fig. 1, at six heights within the PBL and at two different time periods: the first one from 14:30 to 15:30 UTC, the second one later, from 17:45 to 19:00 UTC. This flight strategy provides access to six heights to study the vertical structure of the turbulence within the PBL.

Figure 2 presents the evolution of the potential temperature $(\theta)$ and the wind direction in the PBL at several hours from 05:00 to 18:00 UTC on 20 June 2011. During the day, the PBL warms by about $7 \mathrm{~K}$ and the PBL depth $z_{i}$ grows up to about $1100 \mathrm{~m}$ above ground level. Figure $2 \mathrm{a}$ also shows evidence of a warm advection above the PBL between 05:15 and 11:00 UTC that must be taken into account in the simulation. After 11:00 UTC, the $\theta$ profile hardly changes in the free atmosphere, meaning that the temperature advection is very weak.

Figure $2 \mathrm{~b}$ shows an easterly wind within the PBL, veering to westerly above. The wind intensity remains constant all throughout the day (not shown): it is weak within the PBL (less than $4 \mathrm{~m} \mathrm{~s}^{-1}$ ) and increases with height, up to $10 \mathrm{~m} \mathrm{~s}^{-1}$ at $1500 \mathrm{~m}$.

The water vapour mixing ratio $(r)$ increases from 8 to $10 \mathrm{~g} \mathrm{~kg}^{-1}$ in the PBL until 13:00 UTC and decreases afterward. The temporal evolution of the PBL mean vertical structure is further analysed in Sect. 3.2.

The surface sensible and latent heat fluxes ( $H$ and LE, respectively) measured above various vegetation coverages are presented in Fig. 3. The maximum value of $H$ varies from 100 to $130 \mathrm{~W} \mathrm{~m}^{-2}$ over grass and moor to $450 \mathrm{~W} \mathrm{~m}^{-2}$ over pine forest. LE shows much less variability between vegetation coverage, maximum values varying from 250 to $350 \mathrm{~W} \mathrm{~m}^{-2}$. The measurements at $60 \mathrm{~m}$ height integrate a large footprint and should give flux estimates of the heterogeneous landscape. As such, $H$ measured at $60 \mathrm{~m}$ height is 
(a)

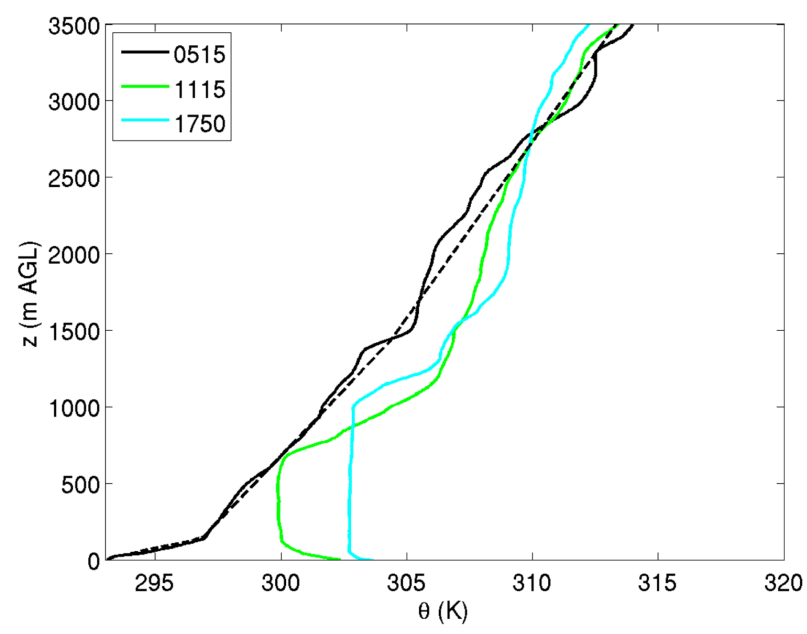

(b)

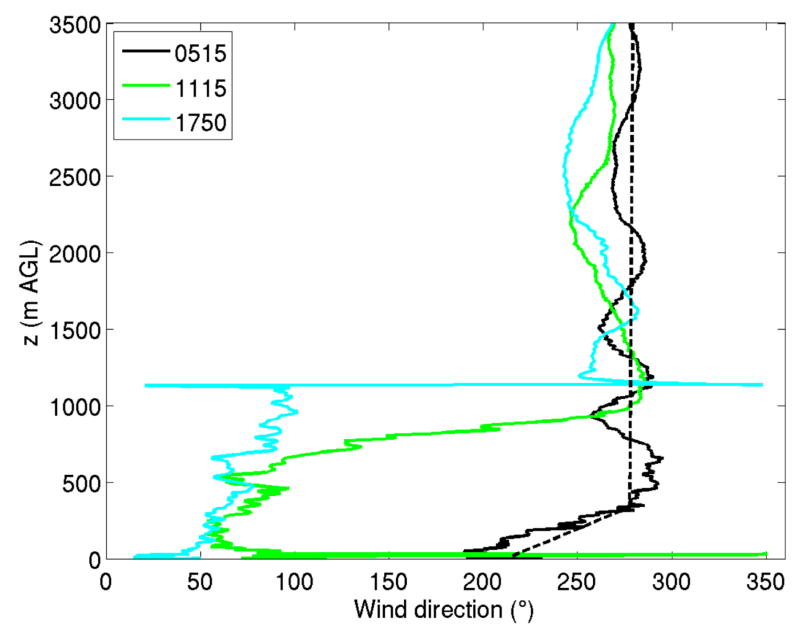

Figure 2. Observed vertical profiles of (a) the potential temperature $\theta$ and (b) the wind direction on 20 June 2011. The black dashed lines represent the initial profiles of the LES.

encompassed in all the other measurements and is close to the moor and grass, the dominant vegetation, which represents about $40 \%$ of the vegetation cover on the plateau.

In this study, the AT is defined as the period from the time when the surface buoyancy flux is maximum, to the time where it goes to 0 (the surface buoyancy flux is defined as the turbulent vertical transport of virtual potential temperature and is approximated as a linear combination of observed surface sensible and latent heat flux). This period varies according to the surface (Lothon et al., 2014). For the moor coverage, whose surface fluxes will be used to drive the simulation of 20 June 2011, this period starts at 12:00 UTC and ends at 1750 UTC, while it ends 20 min earlier when considering $H$ instead of the buoyancy flux. This delay is observed for all the intense observation period (IOP) days of the
BLLAST campaign implying that the latent heat flux reaches its minimum value systematically later than the sensible heat flux. Thus, the forcing timescale of the surface flux decay $\tau_{\mathrm{f}}$ is around $5.8 \mathrm{~h}$ over the moor surface.

\section{LES}

As a complementary tool, a LES is initialized with the BLLAST observations to study turbulence decay of convective boundary layer over a homogeneous and flat surface. The observations from 20 June are used to guide our simulation, like 1 July and 25 June guided the studies of Blay-Carreras et al. (2014b) and Pietersen et al. (2015), respectively. Our aim is not to reproduce a real case but rather to use the BLLAST data set as a benchmark to simulate a boundary layer with the same range of thermal and dynamical instabilities as those observed during BLLAST.

\subsection{LES configuration and initialization}

Our LES is initialized with early morning radiosoundings and forced with homogeneous surface fluxes, based on those measured over the moor surface. Temperature and humidity advection are prescribed. The lateral boundary conditions are periodic.

The LES code from the National Center for Atmospheric Research (Moeng, 1984; Sullivan and Patton, 2011; Patton et al., 2005; Lohou and Patton, 2014) is based on the Boussinesq equations, including conservation laws for momentum and mass and the first law of thermodynamics. The subgrid-scale model includes a turbulent-kinetic-energyeddy-viscosity model suggested by Deardorff (1980), used by Moeng (1984) and improved by Sullivan et al. (1994).

The simulation resolves a domain of $10.24 \mathrm{~km} \times 10.24 \mathrm{~km}$ horizontally and $3.072 \mathrm{~km}$ vertically, with $\Delta x=\Delta y=40 \mathrm{~m}$ and $\Delta z=12 \mathrm{~m}$ of horizontal and vertical resolution, respectively. This results from a compromise between the computation time and three constraints: (1) the domain size and resolution were chosen after a sensitivity study (not shown) so that the LES spectra were able to represent the main characteristics of the observed spectra, (2) the resolution was chosen so that the ratio of $z_{i}$ to $(\Delta x \times \Delta y \times \Delta z)^{1 / 3}$ was large enough to ensure that the results were independent of the resolution (Sullivan and Patton, 2011), and (3) the ratio of $\Delta x$ to $\Delta z$ was kept rather small but with a high enough vertical resolution to correctly represent the entrainment zone (Sullivan and Patton, 2011). The time step evolves during the simulation and is about $1.4 \mathrm{~s}$ for fully convective conditions.

The simulation was initialized early in the morning, in order to ensure a fully turbulent convective PBL by the afternoon. The wind, potential-temperature and specific-humidity initial profiles for the LES were deduced from the 05:15 UTC radiosounding (see dashed lines in Fig. 2 for temperature and wind speed). No geostrophic wind is prescribed. This simple 
(a)

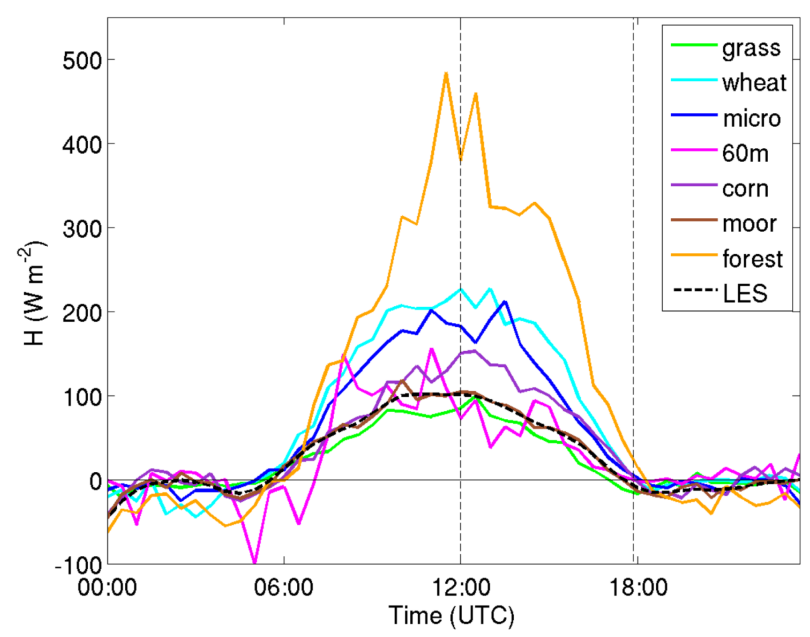

(b)

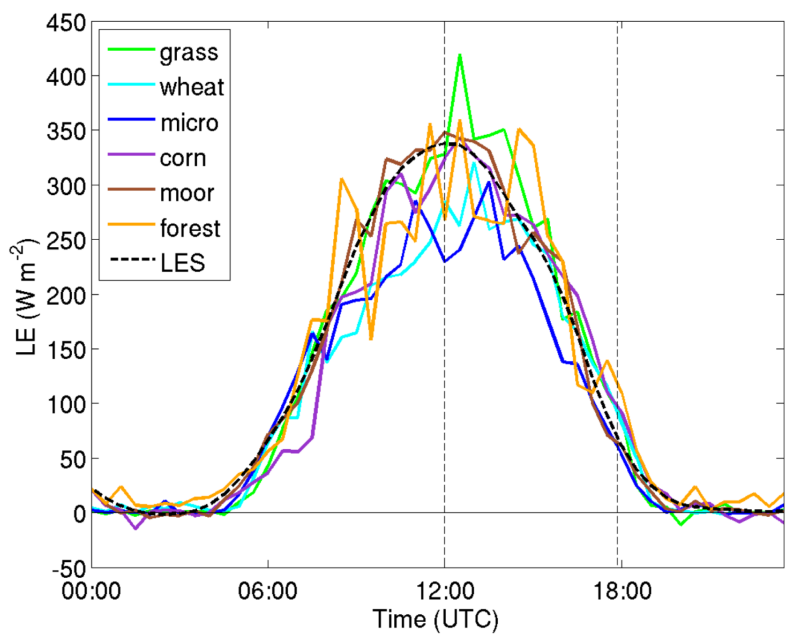

Figure 3. Temporal evolution of (a) surface sensible $(H)$ and (b) latent (LE) heat fluxes over several vegetation coverages on 20 June 2011. Dashed black curves stand for the surface flux used as boundary conditions for the LES. The vertical dashed lines stand for the times of maximum surface buoyancy flux (at 12:00 UTC) and zero value (at 17:50 UTC).

representation of the wind leads to a simulation with very low wind speed, as is the case in the observations, but does not allow us to simulate the shear in wind direction. A homogeneous and flat surface is considered in the LES, with imposed surface fluxes which are those measured at the moor site (Fig. 3).

Vertical profiles of large-scale total advection (horizontal plus vertical advection) of heat and moisture were hourly prescribed in the simulation and linearly interpolated in between. They were derived from the AROME (Application of Research to Operations at Mesoscale) (Seity et al., 2011) forecast model (horizontal resolution of $2.5 \mathrm{~km}$ ), using the 16 grid points in a box surrounding the experimental site. This model confirms predominant zonal advection, especially during the morning.

From 05:15 to 10:00 UTC, temperature advection is important and about $10 \mathrm{~K} \mathrm{day}^{-1}$ from $500 \mathrm{~m}$ up to $1500 \mathrm{~m}$ (not shown). After 11:00 UTC, it decreases and is negligible in the afternoon. This is consistent with what is observed regarding the evolution of the potential temperature (Fig. 2a). From sunrise to 14:00 UTC, the moisture advection is about $-10 \mathrm{~g} \mathrm{~kg}^{-1} \mathrm{day}^{-1}$ from the surface up to $500 \mathrm{~m}$, and about $10 \mathrm{~g} \mathrm{~kg}^{-1}$ day $^{-1}$ above. After 14:00 UTC, the moisture advection weakens (not shown).

The data files used to run this case (initial profiles, surface flux and advection profiles) are available on the website of the BLLAST database (http://bllast.sedoo.fr/database).

\subsection{Evaluation of the simulated boundary layer}

The bracket notation $\langle\psi\rangle$ for any simulated variable $\psi$ is used to represent the 2-D horizontal average over the LES domain. The same notation is used for the 1-D horizontal average of the airborne measurements along the legs. For the surface data set, $\bar{\psi}$ represents the time average notation. For these three types of data sets, the turbulent fluctuations $\psi^{\prime}$ are defined as deviations from the corresponding mean. For a fairer comparison with the simulated variances, the observed variances are estimated by integration of the spectra over the wave number range resolved in the simulation. Finally, all the simulated mean vertical profiles are averaged over $30 \mathrm{~min}$ and depicted, for simplicity, with the bracket notation $\langle\psi\rangle$, which then indicates both horizontal and temporal average.

The evolution of the simulated $\theta$ vertical profiles is compared with observations in Fig. 4a from 05:30 to 17:50 UTC. The simulated $\theta$ is close to the observations in the mixed layer (differences lower than $0.1 \mathrm{~K}$ ) and in the free atmosphere, simulating the change in $\theta$ profile between 05:15 and 11:15 UTC due to the prescribed advection.

In the first $100 \mathrm{~m}$, the differences in stability profile at 11:30 UTC might be due to the different locations of the soundings and the moor site where the surface flux is observed. The 17:30 UTC LES profile is already neutral, whereas the observation at 17:50 UTC still has a superadiabatic region. The differences are due to the fact that as soon as the surface buoyancy fluxes turn negative, the LES potential temperature profile becomes stable in the lower layers of the PBL. This delay between the time when the buoyancy flux goes to 0 and the time when the local gradient of virtual potential temperature changes sign has been observed and analysed in Blay-Carreras et al. (2014a). It can be of the order of $30 \mathrm{~min}$ to $1 \mathrm{~h}$.

Figure $4 \mathrm{~b}$ presents the evolution of the water vapour mixing ratio. The temporal evolution of $r$ profiles shows a well-simulated daily humidification. A departure of $1 \mathrm{~g} \mathrm{~kg}^{-1}$ 
(a)

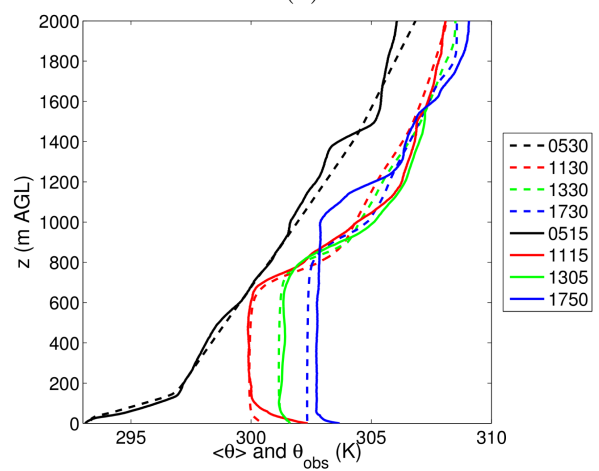

(b)

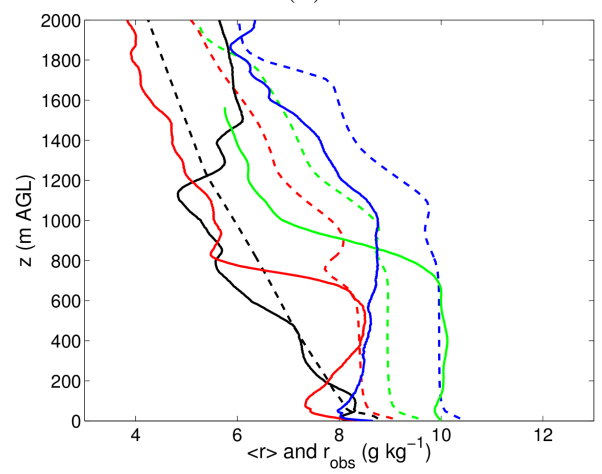

(c)

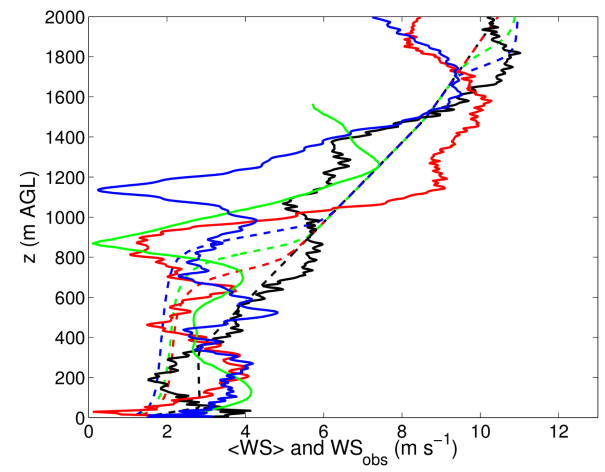

(d)

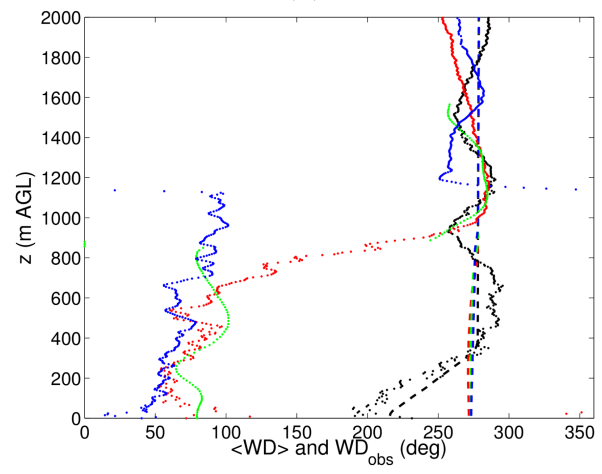

Figure 4. Vertical profiles of (a) $\theta$, (b) $r$, (c) wind speed (WS) and (d) wind direction (WD) observed (solid lines and dotted lines for WD) and obtained by LES (dashed lines).

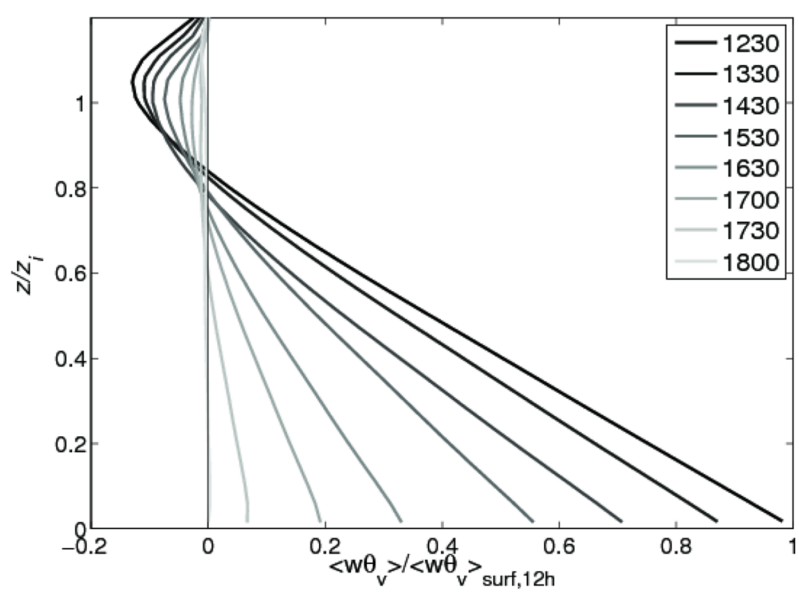

Figure 5. Vertical profiles of the buoyancy flux normalized by the surface buoyancy flux at 12:00 UTC according to the normalized height $z / z_{i}$.

from the value actually observed can be seen at 13:05 and 17:50 UTC.

The horizontal mean wind speed is well reproduced in the simulation during the day: the wind remains weak and about $2 \mathrm{~m} \mathrm{~s}^{-1}$ in the PBL. $u_{*}$ evolves from 0.2 to 0.1 during the afternoon for both observed and simulated data. The wind increases with altitude above the PBL and reaches $10 \mathrm{~m} \mathrm{~s}^{-1}$ at $2000 \mathrm{~m}$. No wind forcing is prescribed in the simulation; therefore, the observed wind direction change from west to east within the mixed layer between 05:30 and 11:30 UTC is not simulated (Fig. 4d). Whilst the wind speed shear is well simulated, the wind direction shear is evidently underestimated. Consequently, shear-driven processes (Pino et al., 2006) might not be as important in the simulation as in the observations.

The simulated vertical profiles of the buoyancy flux normalized by the surface buoyancy flux at the start of the AT (Fig. 5) have quite a classical shape until 13:30 UTC, with a linear decrease with height and negative flux above $0.8 z_{i}$. In the simulation, $z_{i}$ is estimated as the height of the mixed layer, determined with a threshold on the $\theta$ vertical gradient $\left(0.01 \mathrm{~K} \mathrm{~m}^{-1}\right)$. This method was preferred to the one used for radiosoundings (see below) because of the complex humidity profiles which lead to more fluctuating $z_{i}$ estimates. However, the difference between these two estimates is less than $50 \mathrm{~m}$. After 13:30 UTC, the upper layer, characterized by negative entrainment flux, deepens and goes down to 0.6 $z_{i}$ at 18:00 UTC. During the AT the entrainment rate (ratio of the buoyancy flux at the top of the PBL to the buoyancy flux at surface) remains constant and about -0.13 (not shown). Unfortunately, this value cannot be compared to observations since the fluxes deduced from airborne measurements in the PBL vary substantially at that time and because of the lack of statistics on the large scales in a less and less stationary PBL. Flight legs long enough to obtain accurate statistical moment 


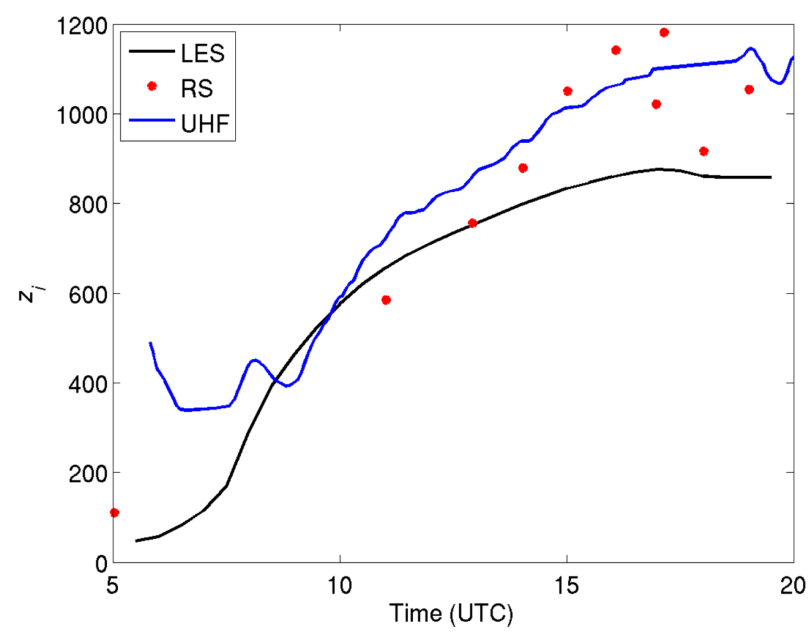

Figure 6. Temporal evolution of $z_{i}$ in the simulation (black), observed by the UHF wind profiler (blue) and depicted using radiosondes (RS), measurements (red dots).

estimates in convective PBL (Lenschow et al., 1994) are even more relevant during the AT.

The temporal evolution of $z_{i}$ has been estimated from ultra high-frequency radar wind profiler (hereafter UHF) and radiosounding measurements and has been compared to the simulation (Fig. 6). $z_{i}$ is estimated from UHF as the maximum of the refractive index structure coefficient (Heo et al., 2003; Jacoby-Koaly et al., 2002). From radiosoundings, $z_{i}$ is estimated as the altitude of the maximum relative humidity below $2500 \mathrm{~m}$ (this criterion has been shown to be consistent in time and height during the BLLAST experiment; Lothon et al., 2014).

Until 09:00 UTC, the UHF detects the residual layer of the previous day. After 10:00 UTC, the $z_{i}$ increase is similarly depicted by the UHF and radiosoundings, with a maximum value of $1100 \mathrm{~m}$. The simulated PBL grows slower than the observed PBL and reaches $850 \mathrm{~m}$. This discrepancy between observed and simulated $z_{i}$ (which is larger than the uncertainty of the $z_{i}$ estimate) might be partly explained by a weaker entrainment effect in the simulation due to a lack of wind shear.

The temporal evolution of the simulated and observed TKE at several heights is presented in Fig. 7.

$\operatorname{TKE}(z, t)=\frac{1}{2}\left(\sigma_{u}^{2}(z, t)+\sigma_{v}^{2}(z, t)+\sigma_{w}^{2}(z, t)\right)$,

where $\sigma_{u}^{2}, \sigma_{v}^{2}$ and $\sigma_{w}^{2}$ are the variances in the horizontal $u$, $v$ and vertical $w$ wind components. For a better comparison, simulated and observed TKE are estimated using the wind component variance deduced from the integration of the spectra over the wave number range of the simulation. By doing this, the TKE associated with large and small eddies observed, but not simulated or resolved in the LES, is removed from the observed TKE. Even with this method, LES

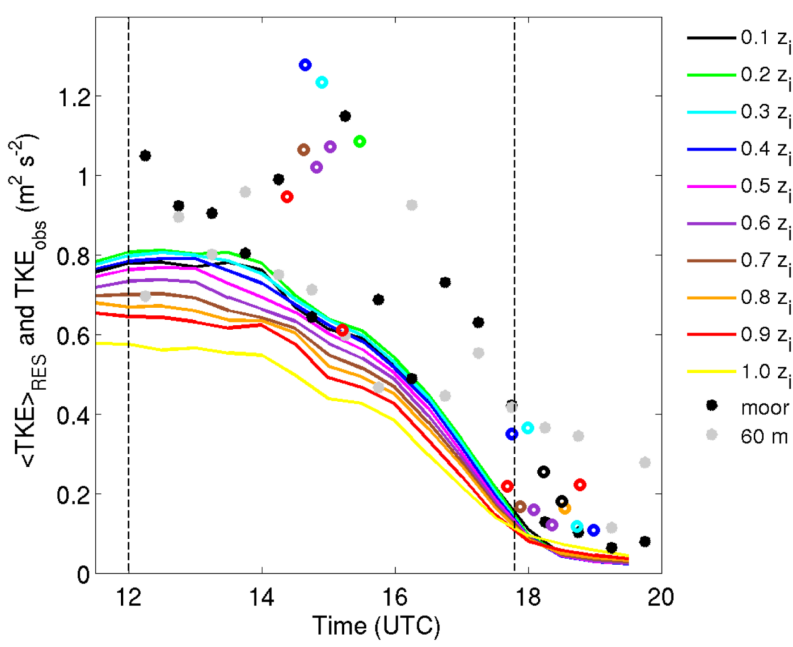

Figure 7. Temporal evolution of the resolved TKE (subscript RES) at different heights in the simulation (different colours). TKE deduced from aircraft and surface (subscript OBS) spectra integrated over the LES spectra wave number range (open and filled circles, respectively). The vertical dashed lines stand for the times of maximum surface buoyancy flux (at 12:00 UTC) and its zero value (at 17:50 UTC).

underestimates the observed TKE by a factor which is sometimes as high as 1.5.

In summary, the simulated boundary layer is comparable to the observed one in terms of boundary layer height, wind speed, and dynamical and thermal stability (not shown) near the surface. The lower development of the PBL height of about $200 \mathrm{~m}$ and the TKE underestimated by a factor of 1.5 can be partly explained by the directional wind shear which is not simulated. The latter might increase the entrainment and the turbulence dynamical production at the top of the boundary layer. Despite these differences regarding the main PBL structure, the simulation is realistic enough to evaluate how the turbulence evolves in a convective boundary layer during the AT and the comparison of the simulated and observed boundary layer will be analysed accordingly.

\section{Spectral analysis method}

A broad overview of the turbulent conditions during the afternoon is depicted through the analysis of the TKE temporal evolution at different heights in the PBL.

The energy distribution among the different eddy scales is then studied through a spectral analysis of the vertical velocity $w$ within the entire PBL. The evolution of $w$ spectral characteristics is analysed by use of an analytical spectral model.

This study focuses on $w$ because simulated and observed $w$ spectra are more easily comparable than the spectra of the horizontal components. Indeed, the horizontal components have significant energy at low wave number (large scales) in 
the observations, which cannot be represented in our simulated domain.

The choice of the analytical spectra is now discussed since several models exist for convective conditions. Among others, the Kaimal et al. (1972, 1976) formulations were established from Kansas experiment observations for the surface layer and from Minnesota experiment observations for the mixed layer. The Kàrmàn spectral model (Kàrmàn, 1948) is also widely used for isotropic turbulence. Højstrup (1982) proposed a more generalized model for $w$ spectra up to $z / z_{i}=0.5$, based on a stability function from neutral to very unstable conditions. However, many of these analytical models were validated for unstable near-surface conditions and most of them are not suitable within the entire convective PBL (Lothon et al., 2009). Among several analytical models tested, the general kinematic spectral model for non-isotropic horizontally homogeneous turbulent field from Kristensen and Lenschow (1989) (hereafter referred to as KL89) is the one which best fits the observed spectra at the surface and in the boundary layer acquired during the BLLAST field campaign (not shown). For $w$, the KL89 model gives

$\frac{S_{\mathrm{Kris}}(k)}{\sigma_{w}^{2}}=\operatorname{co} \frac{l_{w}}{2 \pi} \frac{1+\frac{8}{3}\left(\frac{l_{w} k}{a(\mu)}\right)^{2 \mu}}{\left(1+\left(\frac{l_{w} k}{a(\mu)}\right)^{2 \mu}\right)^{5 /(6 \mu)+1}}$,

where

$a(\mu)=\pi \frac{\mu \Gamma\left(\frac{5}{6 \mu}\right)}{\Gamma\left(\frac{1}{2 \mu}\right) \Gamma\left(\frac{1}{3 \mu}\right)}$,

$k$ being the wave number along the trajectory of the aeroplane or along the west-east axis in the simulation (which is also the mean wind direction in the simulation) and in the mean wind direction for surface measurements. $\Gamma$ is the gamma function. co is a coefficient which adjusts the amount of energy because $\sigma_{w}^{2}$ is calculated over a limited range of wave numbers. This model has two other characteristic parameters: the integral length scale $l_{w}$, which is a characteristic scale corresponding to the scales over which $w$ remains correlated with itself (Lenschow and Stankov, 1986), and a sharpness parameter $\mu$, which governs the curvature of the spectra in the region of the peak, between the low wave number range and the inertial subrange. The larger $\mu$, the sharper the peak. According to Eq. (2), the KL89 model gives the Kaimal et al. (1972) spectrum for $\mu=0.5$ and the Kàrmàn (1948) spectrum for $\mu=1$. It is thus a more generalized model, able to adapt to a larger range of conditions. Note that $l_{w}$ is related to the wavelength of the energy density maximum $\left(\Lambda_{w}\right)$ by a monotonic function of $\mu$ :

$\Lambda_{w}=\left\{\frac{5}{3} \sqrt{\mu^{2}+\frac{6}{5} \mu+1}-\left(\frac{5}{3} \mu+1\right)\right\}^{\frac{1}{2 \mu}} \frac{2 \pi}{a(\mu)} l_{w}$.

This model is fit to each observed and LES spectrum by finding the best $\left[\mathrm{co}, l_{w}, \mu\right]$ triplet using a logarithmic least squares difference method.
The integral scale of $w$ is usually defined from the $w$ autocorrelation function $R_{w}$ as

$L_{w}=\int_{0}^{\infty} R_{w}(r) \mathrm{d} r$

where $r$ is the displacement in space or time. $L_{w}$ gives an estimate of the horizontal size of the convective thermals in the boundary layer. In this study, $L_{w}$ is obtained using an integration until the first 0 of $R_{w}(r)$ (Lenschow and Stankov, 1986). It is used here as a reference to which $l_{w}$ is compared.

In this KL89 analytical spectrum, anisotropy of turbulence is taken into account by varying the integral scale from transverse to lateral spectra. Even considering anisotropy, the spectrum follows the usual $-5 / 3$ slope in the inertial subrange.

For surface-based spectra, 30 min samples are used, which is a good compromise between a sufficient number of eddies and stationary conditions. The spectra based on the aircraft measurements are calculated on legs that are, on average, $35 \mathrm{~km}$. To ensure consistency between simulated and observed spectra, 1-D simulated spectra are considered in the LES. They are calculated along the west-east direction and averaged along the north-south direction. Simulated spectra are estimated above the fourth vertical level (to ensure a negligible contribution of the subgrid scale) and every $96 \mathrm{~m}$ in the vertical. The same sampling is used to calculate the autocorrelation functions for $L_{w}$ estimates.

In order to study the evolution of the spectral slopes in specific domains, the wave number range is split into three parts: (1) the low wave number range $\left\{0, k_{1}\right\}$, (2) the region, $\left\{k_{1}, k_{2}\right\}$, around the maximum energy density at $k=2 \pi / \Lambda_{w}$, and (3) the inertial subrange $\left\{k_{2}, \infty\{\right.$. The limits are defined here as $k_{1}=\pi / \Lambda_{w}$ and $k_{2}=4 \pi / \Lambda_{w}$.

An important part of the study is to verify the level of agreement between the observed or LES spectra and the KL89 analytical model fit. A quality index of the analytical fit is, therefore, estimated based on the ratio between the observed (and LES) spectrum and the analytical spectrum:

$$
\begin{gathered}
I Q_{\mathrm{OBS}}=\frac{1}{N_{\mathrm{OBS}}} \sum_{k}\left|\log \left(\frac{S_{\mathrm{OBS}}(k)}{S_{\mathrm{KL} 89}(k)}\right)\right|, \\
I Q_{\mathrm{LES}}=\frac{1}{N_{\mathrm{LES}}} \sum_{k}\left|\log \left(\frac{S_{\mathrm{LES}}(k)}{S_{\mathrm{KL} 89}(k)}\right)\right|,
\end{gathered}
$$

where $S_{\mathrm{OBS}}$ is the spectrum calculated from the observed $w$, $S_{\text {LES }}$ is the spectrum calculated from the simulated $w$ and $S_{\mathrm{KL} 89}$ is the analytical spectrum given by Eq. 2 that best fits the observed or simulated spectra. $N$ is the number of $k$ values on which $S$ is defined. The larger $I Q_{\mathrm{OBS}}\left(I Q_{\mathrm{LES}}\right)$, the larger the departure between the observed (simulated) and the analytical spectra. No threshold can be found for these fit quality criteria; therefore, values of $I Q_{\mathrm{OBS}}$ and $I Q_{\mathrm{LES}}$ in 
(a)

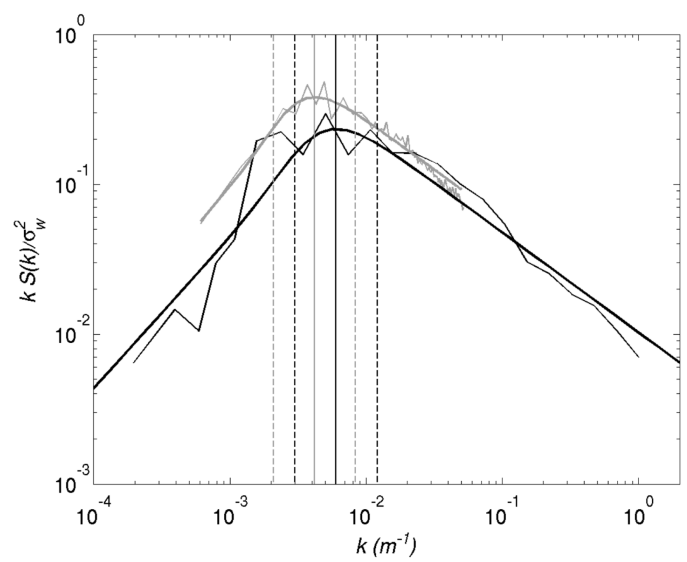

(b)

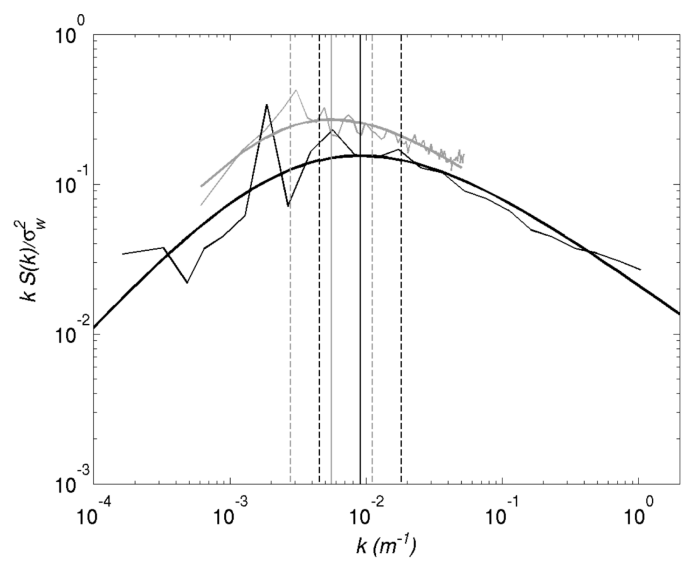

Figure 8. Normalized $w$ spectra at (a) 15:00 and (b) 18:00 UTC from both aircraft (black) and LES (grey), fitted with the KL89 analytical spectral model (thick lines). The vertical continuous lines represent $\Lambda_{w}$, the maximum energy wave number, and the dashed vertical lines represent $k_{1}$ and $k_{2}$, the limits of the low wave number range and of the inertial subrange, defined as $k_{1}=\pi / \Lambda_{w}$ and $k_{2}=4 \pi / \Lambda_{w}$.

convective conditions (from 12:00 to 14:00 UTC) are used as a reference.

Figure 8 presents the normalized spectra of $w$ from both aircraft and simulated data, fitted with the KL89 analytical spectra model. The aircraft (simulated) spectra are calculated at 15:00 and 18:00 UTC and at $z=0.6 z_{i}\left(z=0.6-0.75 z_{i}\right.$ slice-averaged). This figure shows first the ability of the simulation to properly reproduce both the energy production domain and the inertial subrange and, second, the ability of the analytical spectral model to fit well the observed and simulated spectra in mid-afternoon convective conditions (15:00 UTC) and at the end of the afternoon (18:00 UTC).

For these two examples, $I Q_{\mathrm{OBS}}=0.11$ and $I Q_{\mathrm{LES}}=$ 0.02 at $15: 00 \mathrm{UTC}$ and $I Q_{\mathrm{OBS}}=0.10$ and $I Q_{\mathrm{LES}}=0.015$ at 18:00 UTC. In general, the quality index for the observations is about 5 to 10 times larger than for the LES (not shown).
This is due to the lack of statistics on large scales in observations, leading to larger fluctuations in the spectral density energy for the first domain (low wave numbers), whereas the LES spectra are averaged along the north-south direction, reducing the variability.

We also found that the quality index for observed and simulated data generally remained constant until 19:00 UTC, except for a slight increase in $I Q_{\text {LES }}$ for data above $0.6 z / z i$ after 18:30 UTC. This means that the spectra fit is equally reliable throughout the AT, allowing the study of the time evolution of the spectra characteristics from the convective conditions until near-neutral conditions. This result should be highlighted in the case of simulated spectra, given the overly dissipative nature of the subgrid-scale models in the LES (Meneveau and Katz, 2000).

The spectral changes throughout the AT are already noticeable in Fig. 8: $\Lambda_{w}$ shifts toward smaller wavelengths, $l_{w}$ increases, the spectra flatten and the inertial subrange slope changes. This is further quantified and discussed in the following section.

\section{Results}

\subsection{TKE decay within the entire PBL}

Most previous studies investigated either vertically integrated simulated TKE over PBL depth or measured TKE in the surface layer. The TKE decay according to height remains sparsely documented (Grant, 1997; Goulart et al., 2010).

Figure 9a shows the evolution of half-hour averaged hourly vertical profiles of simulated TKE from 11:30 to 18:30 UTC. The profiles show that TKE decreases within the whole depth of the PBL but that there is a 1-hour delay between the start of the decay at the top and the start at the bottom: at 12:30 UTC, the TKE continues to increase in the lower PBL, while it has started to decrease in the upper part. After 15:30 UTC, the decay is homogeneous over the vertical. This differential TKE decay will be named TKE top-down decay hereafter. This result is consistent with the Grimsdell and Angevine (2002) and Lothon et al. (2014) studies which revealed, with remote-sensing observations, a decay of TKE dissipation rates from top to bottom. Shaw and Barnard (2002) also studied the decay with direct numerical simulation (DNS), based on a realistic surface flux decay. They found that the turbulence is maintained at the surface relative to upper layers, which they explain with shear at the surface.

In this study, the simulation likely shows this top-down evolution because the shear in wind direction at the top of the boundary layer is weak and does not maintain the dynamical turbulence production. We can expect a reduced top-down effect in reality since there is shear in direction which is not simulated. 
(a)

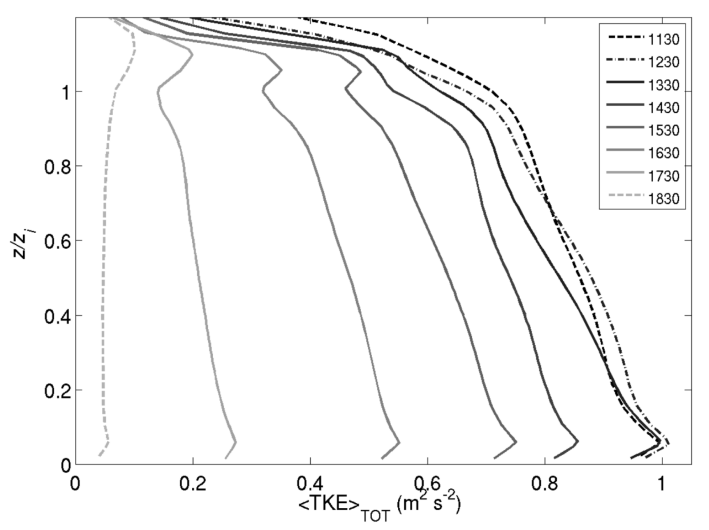

(b)

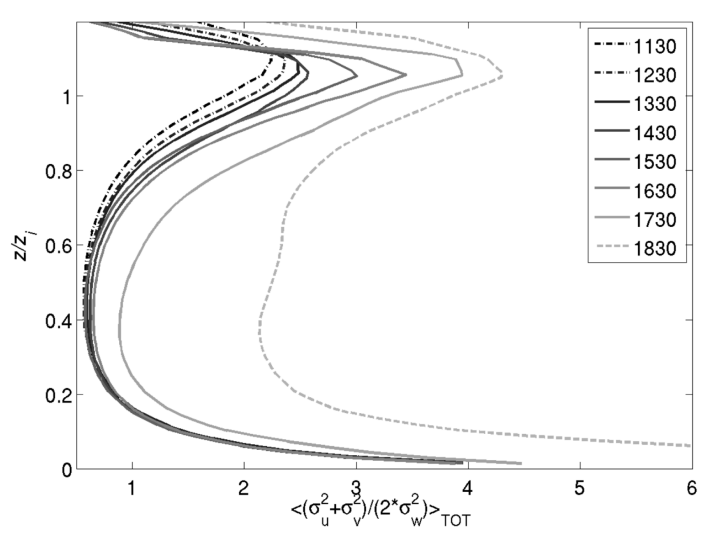

Figure 9. Vertical profiles of the total (resolved and subgrid (subscript TOT)) (a) TKE and (b) anisotropy at several different hours during the AT in the LES.

Turbulence anisotropy (see Fig. 9b), considered here as the ratio of the horizontal to the vertical wind variances, highlights the turbulence structure evolution during the TKE decay. Before 16:30 UTC, turbulence anisotropy remains smaller than unity in the mid-PBL, which is in agreement with the dominant vertical motion of the convective eddies. In the upper and lower parts of the PBL, turbulence anisotropy is larger than unity, due to small vertical velocity variance close to the surface and the entrainment zone (so-called "squashed" turbulence; Lothon et al., 2006).

The anisotropy ratio becomes larger than 1 only after 17:30 UTC in the middle of the PBL but increases close to the top as early as 12:30 UTC. The change in anisotropy, like the TKE, starts early in the upper PBL, with an increasing momentum transfer from vertical to horizontal components during the decay process.

\subsection{Spectral analysis}

\subsubsection{Evolution of the vertical velocity's spectral slopes}

The slopes of the simulated and observed spectra are first analysed because (1) they are key characteristics of the turbulence spectra and (2) the KL89 spectral model assumes for $k S(k)$ the theoretical slope of 1 and $-2 / 3$ for a low and high wave number range, respectively. The slopes are estimated by linear regression on $k S(k)$ for the wave number first and third ranges defined in Sect. 4.

In the low wave number range, the slopes of the simulated and near-surface observed spectra are close to the theoretical value of 1 and remain approximately constant during the whole day (see Fig. 10a). The spectral slopes of airborne measurements are steeper than the theory predicts and vary from 1.5 to 2.5. This result illustrates the weak statistical representativeness of large scales along aircraft flight paths, leading to scattered spectra slope estimates in this wave number range.

In the inertial subrange, both simulated and aircraft data reveal steeper slopes than the theoretical value of $-2 / 3$, even during the fully convective period (Fig. 10b). Steeper inertial subrange slopes were previously observed with vertically pointing ground-based lidar (Lothon et al., 2009) and with airborne high-frequency in situ measurements; (Lothon et al., 2007)). The theoretical $-2 / 3$ slope is based on the hypothesis of isotropic turbulence. Therefore, a possible explanation for these steeper slopes in convective conditions could be the loss of isotropy in real conditions and in particular the role of convective structures and the associated anisotropy. As mentioned before, in Sect. 5.1, convective structures are responsible for anisotropy smaller than 1 . We believe that the more "coherent" or organized the $w$ field, the smaller the anisotropy and the steeper the slope. But this explanation needs further work for confirmation. At the end of the afternoon, the slopes consistently flatten in both LES and aircraft data. This flattening appears to behave differently according to height in two ways: (1) it occurs earlier at the top of the PBL (around 16:00 UTC) than in the lower layers (after $17: 45$ UTC at $0.15 z_{i}$ ); (2) the lower in the PBL the flattening occurs, the smaller it is. These delayed and reduced changes with decreasing altitude are consistent with the constant $-2 / 3$ slope during the whole day near the surface.

\subsubsection{Characteristic length scales}

The integral scale is one of the two spectral characteristics determined from the fit of the KL89 analytical spectral model.

We verified that these integral scale estimates $\left(l_{w}\right)$ were similar to estimates of integral scales $\left(L_{w}\right)$ based on the autocorrelation function (Eq. 5), which is more generally used. The two methods were found to be consistent with each other 
(a)

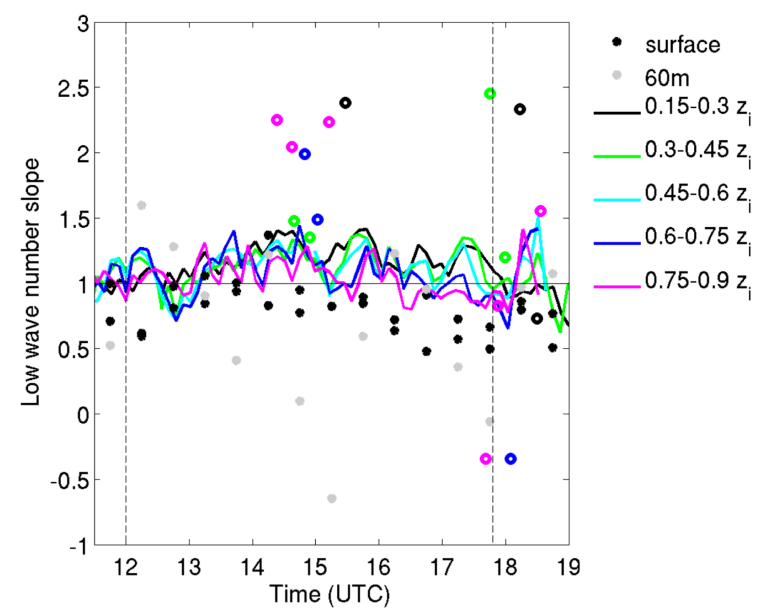

(b)

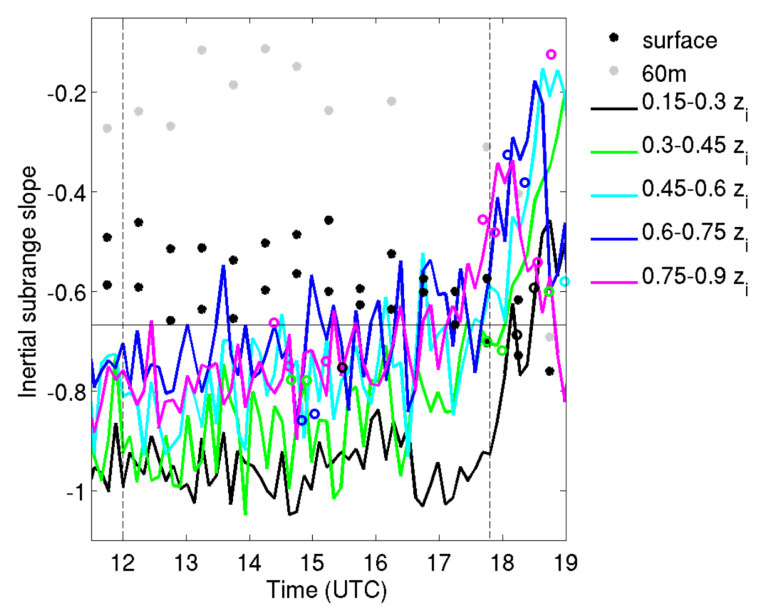

Figure 10. Temporal evolution of the slopes in (a) the low wave number range and (b) the inertial subrange of the $w$ spectra obtained by LES (continuous lines), aircraft and surface measurements (open and filled circles) at different heights (colours). The horizontal black lines stand for the theoretical expected values.

and to give a similar temporal evolution of integral scale (not shown). Hereafter, only $l_{w}$ is considered.

The temporal evolution of $l_{w}$ obtained with aircraft and surface data and with the simulation at different heights is presented in Fig. 11. At midday, the length scales verify what is found in literature, with a value of around $200 \mathrm{~m}$ (about $0.2 z_{i}$ ) in the middle of the mixed layer (Lenschow and Stankov, 1986, with aircraft observations and Dosio et al. (2005) with LES, among others). Smaller length scales are observed and simulated at the top and at the bottom of the mixed layer because of "squashed" eddies near the interfaces. $l_{w}$ remains approximately constant until 17:00 UTC and then increases above $0.15 z_{i}$ for both LES and aircraft data. The higher the considered level, the sharper the $l_{w}$ increase.

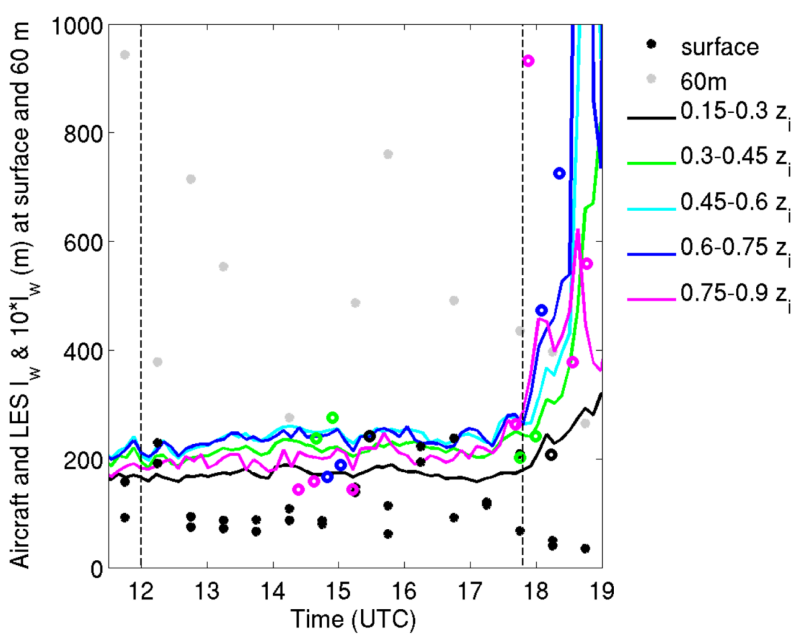

Figure 11. Temporal evolution of $l_{w}$ calculated from the KL89 analytical model fit on LES (continuous lines), aircraft (open circles) and surface (closed circles) spectra at different heights (different colours). Note that $l_{w}$ at surface and at $60 \mathrm{~m}$ is multiplied by a factor of 10. The vertical dashed lines stand for the times of maximum surface buoyancy flux (at 12:00 UTC) and its zero value (at 17:50 UTC).

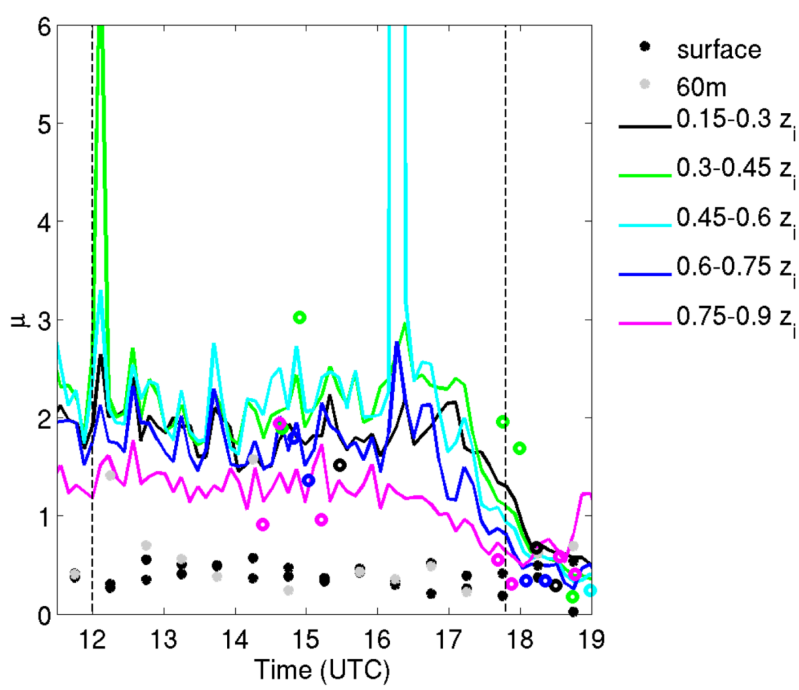

Figure 12. Temporal evolution of the parameter $\mu$, obtained from the KL89 analytical model, by using LES (continuous lines), aircraft (open circles) and surface (closed circles) data. The vertical dashed lines stand for the times of maximum surface buoyancy flux (at 12:00 UTC) and its zero value (at 17:50 UTC).

Close to the surface, $l_{w}$ remains constant until 17:00 UTC at a height of $10 \mathrm{~m}$ and then decreases to $5 \mathrm{~m}$. As expected, the $60 \mathrm{~m}$ mast data provide longer $l_{w}$ than those at the surface but with a large scatter (between 30 and $80 \mathrm{~m}$ ), making it difficult to estimate $l_{w}$ tendency with time at that height. 


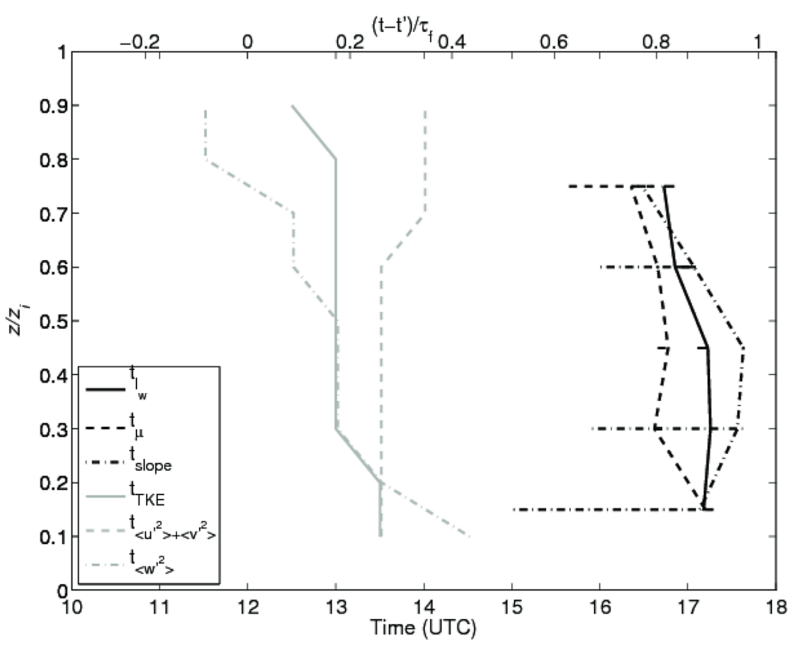

Figure 13. Vertical profiles of the timings of changes observed in the evolution of the TKE, the vertical and horizontal variances, $l_{v}$, $\mu$, and the inertial subrange slope of $w$ spectra. $t^{\prime}$ is defined as the time when $H$ is maximum (i.e. at 12:00 UTC).

\subsubsection{Shape of the spectra}

The spectral shape is depicted by the $\mu$ sharpness parameter (Eq. 2). Figure 12 shows the temporal evolution of $\mu$ that gives the best fit of the spectra for simulation, aircraft and surface data. Above $0.15 z_{i}, \mu$ remains constant at a value of about 2 until 16:00 UTC, aircraft and simulated data giving similar results. These results are similar to those found by Lothon et al. (2009) with ground-based lidar, who also observed sharper spectra than the Kaimal spectra $(\mu=0.5)$ in the middle of the PBL. After 16:00 UTC, $\mu$ decreases, meaning that the turbulence spectra flatten during the late afternoon transition associated with a broadening of the energy containing wave number range above $0.15 z_{i}$. This seems consistent with the theoretical spectral analysis by Goulart et al. (2010) (see their Fig. 6, bottom, in the convective boundary layer). By contrast, close to the surface and at $60 \mathrm{~m}$ height, $\mu \approx 0.5$ throughout the day, which corresponds to the spectral model from Kaimal et al. (1972) and means that the energy wave number range remains large during the afternoon. In the KL89 analytical model, $\mu, l_{w}$ and $\Lambda_{w}$ are linked by Eq. (4), which gives higher $\Lambda_{w} / l_{w}$ for higher $\mu$ (Lenschow and Stankov, 1986). As shown in Fig. 8, $\Lambda_{w}$ drifts slightly toward smaller eddies. Keeping in mind that $\Lambda_{w}$ represents the distance between two structures and $l_{w}$ represents the width of a structure, this means that during the afternoon, the thermals become closer to each other, whereas the increase in $l_{w}$ means the thermals become larger. This is consistent with a decreasing skewness of $w$ as time evolves, which we find in both observation and LES (not shown).

\subsection{Timing of the changes}

The previous results illustrate the changes in turbulence characteristics throughout the afternoon according to height. The times when these characteristics start to change are now quantified using the simulation data above $0.15 z_{i}$, the tower measurements at $60 \mathrm{~m}$, and the near surface moor and corn data. The time of change for a parameter $x$ is denoted by $t_{x}$ (Fig. 13). For $\mu, l_{w}$ and the slope, it is the time when the decay rates of these spectra parameters depart from their mean value by more than 3 times their standard deviation (the decay rates are estimated over $1.5 \mathrm{~h}$ and their means and standard deviations are calculated between noon and 14:00 UTC). Because of the diurnal cycle of the TKE and the horizontal and vertical velocity variances, this method could not be applied to determine the time change in these parameters. $t_{\mathrm{TKE}}, t_{<w^{\prime 2}>}$ and $t_{<u^{\prime 2}>+<v^{\prime 2}>}$ were thus the times when the decaying rate of the parameter (estimated by linear regression over $1.5 \mathrm{~h}$ ) becomes larger than for an arbitrary threshold of $-1.11 \times 10^{-5} \mathrm{~m}^{2} \mathrm{~s}^{-3}$ (meaning a TKE decrease of $-0.02 \mathrm{~m}^{2} \mathrm{~s}^{-2}$ for a time interval of $30 \mathrm{~min}$ ).

As already noticed in Sect. 5.1, the TKE first decreases at the top of the boundary layer half an hour after the start of the AT (Fig. 13). That is, once the surface flux starts to decrease, the surface-driven turbulence does not rise up to the top of the boundary layer anymore. This indicates that turbulence decreases first at the top of the PBL, whereas it is maintained longer under $0.15 z_{i}$. The TKE decrease is exclusively driven by the vertical velocity variance, which decreases at the top of the PBL $1.5 \mathrm{~h}$ before the maximum of the surface buoyancy flux. The early decrease in the vertical velocity variance is counterbalanced in TKE by the delayed change in the horizontal wind variance. This implies an increase in the anisotropy of the velocity variances in the early stage of surface flux decrease.

The change in other spectral parameters (length scale, sharpness and slope) is observed much later, during the last $2 \mathrm{~h}$ before the zero surface buoyancy flux. The vertical profiles of $t_{l_{w}}, t_{\text {slope }}$ and $t_{\mu}$ indicate an increase in integral scales, a flattening of the inertial subrange slope and a flattening of the spectra, appearing first at the top of the boundary layer and rapidly reaching the lower layers.

Near the surface and at $60 \mathrm{~m}$, a very weak evolution of the spectra is observed. The spectra keep the same sharpness, similar to Kaimal spectra, with a constant slope of $-2 / 3$ in the inertial subrange, and a very slightly decreasing $l_{w}$. These results are consistent with the spectral behaviour above 0.15 $z_{i}$. Indeed, $\mu$ decreases from around 2 in convective conditions to 0.5 at the end of the AT in the whole upper layer, and the $l_{w}$ increase in the upper layers is less and less pronounced with decreasing height. 


\subsection{Discussion}

The above analysis of the evolution of the turbulence structure during the AT suggests that we should separate this period into two stages: early and late afternoon.

In the early afternoon, from the occurrence of the buoyancy maximum until about $2 \mathrm{~h}$ before sunset, (1) the TKE decreases within the whole PBL, with a 1-hour delay between the upper part (earlier decay) and the lower part of the PBL (postponed decay), (2) the vertical profile of anisotropy does not change much within the PBL, except close to the top, and (3) the spectra maintain the characteristics of the fully developed convective boundary layer, with similar integral scales and sharpness parameters.

In the late afternoon, from $2 \mathrm{~h}$ before sunset until when the surface buoyancy flux reduces to 0, (1) the TKE decreases more rapidly than during the early AT within the whole PBL, (2) turbulence anisotropy increases abruptly within the PBL, starting initially near the PBL top, and (3) the shape of the spectra evolves, with a decrease in the sharpness parameter, a flattening of the inertial subrange slope, and an increase in the integral length scales in the mid and upper PBL. The higher in the PBL the integral scales are, the stronger their increase, with very slight changes in the spectra shape observed close to the surface.

The two stages of the TKE decay found in this study remain consistent with previous results found by Nadeau et al. (2011) and Rizza et al. (2013a). Both authors showed a decrease in the TKE following a $t^{-n}$ power law with a continuous increase in $n$. Nadeau et al. (2011) defined two main stages characterized by $n$ around 2 and 6. Rizza et al. (2013a) added a preliminary stage with $n$ equal to 1 . Our first stage includes $t^{-1}$ and $t^{-2}$ power laws, and the second one includes $t^{-6}$. However, it seems somehow arbitrary to characterize our two stages by a specific value of $n$ since it evolves continuously. This study focuses on the link between the structure of the turbulence and the TKE evolution. Also, the TKE budget evolution in time was not of any help to explain the two stages of the TKE decrease. Whilst the different terms do decrease with time, their respective contribution to the TKE tendency hardly changes from the first to the second stages (not shown).

Our understanding of the two different stages of the AT is that during the early afternoon, the buoyancy flux remains large and its decay is slow enough to give the PBL time to adjust to the change and to remain in quasi-steady balance. In other words, the convective timescale $t_{*}$ is small enough ( $\sim 9 \mathrm{~min})$ relative to $\tau_{\mathrm{f}}(\sim 5.8 \mathrm{~h})$ to allow this quasi-steady state. The spectral characteristics remain similar to what they are at maximum surface buoyancy flux. Buoyancy remains a dominant influence during this stage, leading to the vertical velocity variance and convective structures being predominant. The latter, with a characteristic horizontal length typically linked to the PBL depth, could maintain a sharp spectral peak. The predominance of convective structures might also be the cause of the steep inertial subrange slope. Close to the surface, where these convective structures are not yet well shaped, the inertial subrange slope is $-2 / 3$.

On the contrary, during the late afternoon, $t_{*}$ increases (about $20 \mathrm{~min}$ at 17:00 UTC) and the buoyancy flux gets too small for the PBL to maintain the vertical consistency of the turbulence structure from the surface up to the top of the PBL. The impact of surface buoyancy decreases faster than that of entrainment during this period: although the entrainment flux magnitude diminishes, entrainment occurs over a broader vertical depth extending down to $0.6 z_{i}$ (Fig. 5).

An increase in the entrainment role could explain the increase in the vertical velocity integral scales (Lohou et al., 2010; Canut et al., 2010), which is observed in the upper PBL during the late afternoon during our BLLAST case. The increase in vertical velocity integral scales is consistent with the results of Sorbjan (1997) but disagrees with those of Pino et al. (2006). This could be due to the progressive cessation of the surface flux in Sorbjan (1997) and Grant (1997) versus the sudden shut-off in Pino et al. (2006). In the surface layer, the decrease in the integral scales is consistent with the observations made by Grant (1997) and with the results of Kaimal et al. (1972).

The flattening observed in the inertial subrange during the late afternoon is difficult to explain because one might expect a steeper slope in inertial subrange when the flow becomes less turbulent, assuming that the smaller scales will dissipate faster than the larger scales. However, hypotheses could be made to explain the observed flattening of the spectra in the inertial subrange: (1) the increase in anisotropy might be associated with such a change in the cascade; (2) if the turbulence is now freely decaying, without influence of coherent structures and vertical velocity dominance, the cascade could become more efficient, resulting in a flattening slope according to Moeng and Wyngaard (1988). In any case, it seems that with the turbulence being no longer fully forced, the criteria for locally isotropic turbulence are no longer met. The theoretical model of the TKE spectrum proposed by Goulart et al. (2010) could be an interesting tool to further understand this slope change since it considers anisotropy of turbulence through the KL89 analytical spectrum and also considers the terms of the TKE budget which might impact on the inertial subrange slope.

The progressive shut-off of the surface heat fluxes is shown to be an important aspect of the AT. Nieuwstadt and Brost (1986) and Pino et al. (2006), who analysed simulations with a sudden shut-off of the buoyancy flux, pointed out what they called a demixing process, which implies a negative buoyancy flux within the whole PBL. The impact of entrainment in this case might be overestimated. Similar to Sorbjan (1997), when progressively transitioning through the afternoon from a surface-buoyancy-dominated to an entrainment-dominated regime, the demixing process is strongly reduced and limited to the upper half of the PBL. 
One might wonder whether these results could be impacted by the initial conditions. The use of all the airborne measurements acquired during the BLLAST experiment shows the general trend of an increasing integral scale during the late afternoon (not shown). However, it would be useful to complete this study with some additional simulations either targeting other BLLAST IOPs or performing some sensitivity analyses. Wind shear could be an important focus as Nieuwstadt and Brost (1986), Pino et al. (2006) and Goulart et al. (2010) found that strong wind shear at the top and bottom of the PBL delays the decay.

\section{Conclusions}

This study is based on the use of analytical spectra to depict and quantify changes in the vertical velocity spectra throughout the AT and according to height. BLLAST aircraft and surface station measurements are used to study the turbulence spectral evolution on 20 June 2011. A large-eddy simulation constrained by observed conditions during BLLAST, but significantly simplified, allows us to investigate a continuous spectral analysis in time and height.

The simulated data, even with simplified forcings and initial conditions, are in satisfactory agreement with the airborne, radiosonde and surface observations. The model reasonably simulates the turbulence structure through the afternoon with a resolution and a domain size allowing a good fit of the simulated spectra with the Kristensen and Lenschow (1989) analytical model above $0.15 z_{i}$.

Two main conclusions can be drawn from this study, giving essential information on the turbulence evolution in time and height:

1. This study shows for the first time the different steps occurring during the AT, which is defined as the period starting at the maximum surface buoyancy flux and ending when the buoyancy flux reaches 0 . The early afternoon (first phase from 0 to $0.75 \tau_{\mathrm{f}}$ ) is characterized by a low-rate decrease in the energy level, but the turbulence characteristics remain similar to those during fully convective conditions: similar turbulence length scales and cascade characteristics from large to small eddies. During the late afternoon (second phase from 0.75 to $1 \tau_{\mathrm{f}}$ ), TKE decay rates increase and turbulence characteristics evolve rapidly, implying a very different eddy size and energy transfer.

2. The second important point concerns the turbulence evolution along the vertical. The changes observed either in TKE decay (during the early afternoon) or in $w$ spectral shape (during the late afternoon) start at the top of the boundary layer. Furthermore, the higher the spectra within the PBL, the stronger their shape changes. These results show that the top of the boundary layer is affected by the changes first.
Acknowledgements. The BLLAST field experiment was made possible thanks to the contribution of several institutions and organisations: INSU-CNRS (Institut National des Sciences de l'Univers, Centre national de la Recherche Scientifique, LEFE-IMAGO program), Météo-France, Observatoire Midi-Pyrénées (University of Toulouse), EUFAR (EUropean Facility for Airborne Research) BLLATE-1\&2, COST ES0802 (European Cooperation in the field of Scientific and Technical) and the Spanish MINECO projects CGL2009-08609, CGL2012-37416-C04-03 and CGL201113477-E. The field experiment would not have taken place without the significant contribution of all participating European and American research groups. The Piper Aztec research airplane is operated by SAFIRE, which is a unit supported by INSUCNRS, Météo-France and the French Spatial Agency (CNES). The BLLAST field experiment was hosted by the instrumented site of Centre de Recherches Atmosphériques, Lannemezan, France (Observatoire Midi-Pyrénées, Laboratoire d'Aérologie). Its $60 \mathrm{~m}$ tower is partly supported by the POCTEFA/FLUXPYR European program. BLLAST data are managed by SEDOO, from Observatoire Midi-Pyrénées. Since 2013, the French ANR has supported BLLAST analysis. See http://bllast.sedoo.fr for all contributions. We particularly thank Eric Pardyjak, Oscar Hartogensis, Dominique Legain and Frédérique Saï for providing the surface measurements used in this study. We are also grateful to Bruno Piguet for the first processing of the Piper Aztec data set and to Dominique Legain and the CNRM-4M team for the frequent radiosoundings. Computer facilities for the large-eddy simulation were provided by CALMIP (Calcul en Midi-Pyrénées, France).

Edited by: E. Pardyjak

\section{References}

Blay-Carreras, E., Pardyjak, E. R., Pino, D., Alexander, D. C., Lohou, F., and Lothon, M.: Countergradient heat flux observations during the evening transition period, Atmos. Chem. Phys., 14, 9077-9085, doi:10.5194/acp-14-9077-2014, 2014a.

Blay-Carreras, E., Pino, D., Vilà-Guerau de Arellano, J., van de Boer, A., De Coster, O., Darbieu, C., Hartogensis, O., Lohou, F., Lothon, M., and Pietersen, H.: Role of the residual layer and large-scale subsidence on the development and evolution of the convective boundary layer, Atmos. Chem. Phys., 14, 4515-4530, doi:10.5194/acp-14-4515-2014, 2014b.

Brazel, A., Fernando, H., Hunt, J., Selover, N., Hedquist, B., and Pardyjak, E.: Evening Transition Observations in Phoenix, Arizona, J. Appl. Meteorol., 44, 99-112, 2005.

Canut, G., Lothon, M., Saïd, F., and Lohou, F.: Observation of entrainment at the interface between monsoon flow and the Saharan Air Layer, Quarterly Journal of the Royal Meteorological Society, 136, 34-46, 2010.

Carvalho, J., Degrazia, G., Anfossi, D., Goulart, A., Cuchiara, G. C., and Mortarini, L.: Simulating the characteristic patterns of the dispersion during sunset PBL, Atmos. Res., 98, 274-284, doi:10.1016/j.atmosres.2010.06.009, 2010.

Casso-Torralba, P., Vilà-Guerau de Arellano, J., Bosveld, F., Soler, M., Vermeulen, A., Werner, C., and Moors, E.: Diurnal and vertical variability of the sensible heat and carbon dioxide budgets 
in the atmospheric surface layer, J. Geophys. Res., 113, D12119, doi:10.1029/2007JD009583, 2008.

Cole, G. and Fernando, H.: Some aspects of the decay of convective turbulence, Fluid Dynam. Res., 23, 161-176, 1998.

Davidson, P.: Turbulence: An introduction for Scientists and Engineers, Oxford University Press Inc., New York, 2004.

Deardorff, J.: Convective velocity and temperature scales for the unstable planetary boundary layer and for Rayleigh convection, J. Atmos. Sci., 27, 1211-1215, 1970.

Deardorff, W.: Stratocumulus-capped mixed layers derived from a three-dimensional model, Bound.-Lay. Meteorol., 18, 495-527, 1980.

Dosio, A., Vilà-Guerau De Arellano, J., and Holtslag, A. A. M.: Relating Eulerian and Lagrangian Statistics for the Turbulent Dispersion in the Atmospheric Convective Boundary Layer, J. Atmos. Sci., 62, 1175-1191, 2005.

Fernando, H., Princevac, M., Pardyjak, E., and Data, A.: The decay of convective turbulence during evening transition period, in: 11th Conference on Mountain Meteorology and MAP Meeting, Bartlett (NH), USA, paper 10.3, 2004.

Fitzjarrald, D. R., Freedman, J. M., Czikowsky, M. J., Sakai, R. K., and Moraes, O. L. L.: Momentum and scalar transport during the decay of CBL turbulence, 16th AMS Symposium on boundary layers and turbulence, 2004.

Gioli, B., Miglietta, M., Vaccari, F. P., Zaldei, A., and De Martino, B.: The Sky Arrow ERA, an innovative airborne platform to monitor mass, momentum and energy exchange of ecosystems, Ann. Geophys., 49, 109-116, 2006, http://www.ann-geophys.net/49/109/2006/

Goulart, A., Degrazia, G., Rizza, U., and Anfossi, D.: A theoretical model for the study of convective turbulence decay and comparison with large-eddy simulation data, Bound.-Lay. Meteorol., 107, 143-155, 2003.

Goulart, A., Bodmann, B., Vilhena, M., Soares, P., and Moreira, D.: On the Time Evolution of the Turbulent Kinetic Energy Spectrum for Decaying Turbulence in the Convective Boundary Layer, Bound.-Lay. Meteorol., 138, 61-75, doi:10.1007/s10546010-9546-4, 2010.

Grant, A. L. M.: An observational study of the evening transition boundary-layer, Q. J. Roy. Meteorol. Soc., 123, 657-677, 1997.

Grimsdell, A. W. and Angevine, W. M.: Observations of the afternoon transition of the convective boundary layer, J. Appl. Meteorol., 41, 3-11, 2002.

Heo, B., Jacoby-Koaly, S., Kim, K., Campistron, B., Bénech, B., and Jung, E.: Use of the Doppler spectral width to improve the estimation of the convective boundary layer height from UHF wind profiler observations, J. Atmos. Ocean. Technol., 20, 408424, 2003

Højstrup, J.: Velocity spectra in the unstable planetary boundary layer, J. Atmos. Sci., 39, 2239-2248, 1982.

Jacoby-Koaly, S., Campistron, B., Bernard, S., Bénech, B., Ardhuin-Girard, F., Dessens, J., Dupont, E., and Carissimo, B.: Turbulent dissipation rate in the boundary layer via uhf wind profiler doppler spectral width measurements, Bound.-Lay. Meteorol., 103, 361-389, 2002.

Kaimal, J., Wyngaard, J., and Coté, O.: Spectral characteristics of surface layer turbulence, Q. J. Roy. Meteorol. Soc., 98, 653-689, 1972.
Kaimal, J., Wyngaard, J., Haugen, D., Coté, O., and Izumi, Y.: Turbulence structure in the convective boundary layer, J. Atmos. Sci., 33, 2152-2169, 1976.

Kàrmàn, T.: Progress in the statistical theory of turbulence, Proc. Natl. Acad. Sci. USA, 34, 530-539, 1948.

Kristensen, L. and Lenschow, D. H.: The spectral velocity tensor for homogeneous boundary-layer turbulence, Bound.-Lay. Meteorol., 47, 149-193, doi:10.1177/1553350614532679, 1989.

Legain, D., Bousquet, O., Douffet, T., Tzanos, D., Moulin, E., Barrie, J., and Renard, J.-B.: High-frequency boundary layer profiling with reusable radiosondes, Atmos. Meas. Tech., 6, 21952205, doi:10.5194/amt-6-2195-2013, 2013.

Lenschow, D. H. and Stankov, B. B.: Length scales in the convective boundary layer, J. Atmos. Sci., 43, 1198-1209, 1986.

Lenschow, D. H., Mann, J., and Kristensen, L.: How Long is Long Enough When Measuring Fluxes and Other Turbulence Statistics?, J. Atmos. Ocean. Technol., 11, 661-673, 1994.

Lohou, F. and Patton, E. G.: Surface Energy Balance and Buoyancy Response to Shallow Cumulus Shading, J. Atmos. Sci., 71, 665682, doi:10.1175/JAS-D-13-0145.1, 2014.

Lohou, F., Saïd, F., Lothon, M., Durand, P., and Serça, D.: Impact of Boundary-Layer Processes on Near-Surface Turbulence Within the West African Monsoon, Bound.-Lay. Meteorol., 136, 1-23, doi:10.1007/s10546-010-9493-0, 2010.

Lothon, M., Lenschow, D., and Mayor, S.: Coherence and Scale of Vertical Velocity in the Convective Boundary Layer from a Doppler Lidar, Bound.-Lay. Meteorol., 121, 521-536, doi:10.1007/s10546-006-9077-1, 2006.

Lothon, M., Lenschow, D. H., and Schanot, A.: Statusreminder report on $\mathrm{C}-130$ air-motion measurements. Test of DYCOMS-II new datasets, Internal report, NCAR-RAF, available at: https://www.eol.ucar.edu/raf/Projects/DYCOMS-II/ DYCOMS.report1_win07.pdf (last access: 4 January 2007), 2007.

Lothon, M., Lenschow, D., and Mayor, S.: Doppler Lidar Measurements of Vertical Velocity Spectra in the Convective Planetary Boundary Layer, Bound.-Lay. Meteorol., 132, 205-226, doi:10.1007/s10546-009-9398-y, 2009.

Lothon, M., Lohou, F., Pino, D., Couvreux, F., Pardyjak, E. R., Reuder, J., Vilà-Guerau de Arellano, J., Durand, P, Hartogensis, O., Legain, D., Augustin, P., Gioli, B., Lenschow, D. H., Faloona, I., Yagüe, C., Alexander, D. C., Angevine, W. M., Bargain, E, Barrié, J., Bazile, E., Bezombes, Y., Blay-Carreras, E., van de Boer, A., Boichard, J. L., Bourdon, A., Butet, A., Campistron, B., de Coster, O., Cuxart, J., Dabas, A., Darbieu, C., Deboudt, K., Delbarre, H., Derrien, S., Flament, P., Fourmentin, M., Garai, A., Gibert, F., Graf, A., Groebner, J., Guichard, F., Jiménez, M. A., Jonassen, M., van den Kroonenberg, A., Magliulo, V., Martin, S., Martinez, D., Mastrorillo, L., Moene, A. F., Molinos, F., Moulin, E., Pietersen, H. P., Piguet, B., Pique, E., RománCascón, C., Rufin-Soler, C., Saïd, F., Sastre-Marugán, M., Seity, Y., Steeneveld, G. J., Toscano, P., Traullé, O., Tzanos, D., Wacker, S., Wildmann, N., and Zaldei, A.: The BLLAST field experiment: Boundary-Layer Late Afternoon and Sunset Turbulence, Atmos. Chem. Phys., 14, 10931-10960, doi:10.5194/acp14-10931-2014, 2014.

Meneveau, C. and Katz, J.: Scale-Invariance and Turbulence Models for Large-Eddy Simulation, Annu. Rev. Fluid Mech., 32, 132,2000 
Moeng, C. H.: A large-eddy-simulation model for the study of planetary boundary-layer turbulence, J. Atmos. Sci., 41, 2052-2062, 1984.

Moeng, C.-H. and Wyngaard, J.: Spectral-analysis of large-eddy simulations of the convective boundary-layer, J. Atmos. Sci., 45, 3573-3587, 1988.

Monin, A. and Yaglom, A.: Statistical fluid mechanics, vol. 2, The MIT Press, Massachussets, 1975.

Nadeau, D., Pardyjak, E., Higgins, C., Fernando, H., and Parlange, M.: A Simple Model for the Afternoon and Early Evening Decay of Convective Turbulence Over Different Land Surfaces, Bound.Lay. Meteorol., 141, 301-324, doi:10.1007/s10546-011-9645-x, 2011.

Nieuwstadt, F. T. M. and Brost, R. A.: The decay of convective turbulence, J. Atmos. Sci., 43, 532-546, 1986.

Patton, E. G., Sullivan, P. P., and Moeng, C. H.: The Influence of Idealized Heterogeneity on Wet and Dry Planetary Boundary Layers Coupled to the Land Surface, J. Atmos. Sci., 62, 20782097, 2005.

Pietersen, H. P., Vilà-Guerau de Arellano, J., Augustin, P., van de Boer, A., de Coster, O., Delbarre, H., Durand, P., Fourmentin, M., Gioli, B., Hartogensis, O., Lohou, F., Lothon, M., Ouwersloot, H. G., Pino, D., and Reuder, J.: Study of a prototypical convective boundary layer observed during BLLAST: contributions by large-scale forcings, Atmos. Chem. Phys., 15, 42414257, doi:10.5194/acp-15-4241-2015, 2015.

Pino, D., Jonker, H., Vilà-Guerau De Arellano, J., and Dosio, A.: Role of Shear and the Inversion Strength During Sunset Turbulence Over Land: Characteristic Length Scales, Bound.-Lay. Meteorol., 121, 537-556, doi:10.1007/s10546-006-9080-6, 2006.

Rizza, U., Miglietta, M., Degrazia, G., Acevedo, O., and Marques Filho, E.: Sunset decay of the convective turbulence with Large-Eddy Simulation under realistic conditions, Physica A: Statistical Mechanics and its Applications, 392, 4481-4490, doi:10.1016/j.physa.2013.05.009, 2013a.
Rizza, U., Miglietta, M. M., Acevedo, O. C., Anabor, V., Degrazia, G. a., Goulart, A. G., and Zimmerman, H. R.: Large-eddy simulation of the planetary boundary layer under baroclinic conditions during daytime and sunset turbulence, Meteorol. Appl., 20, 56-71, doi:10.1002/met.1284, 2013b.

Saïd, F., Corsmeier, U., Kalthoff, N., Kottmeier, C., Lothon, M., Wieser, a., Hofherr, T., and Perros, P.: ESCOMPTE experiment: intercomparison of four aircraft dynamical, thermodynamical, radiation and chemical measurements, Atmos. Res., 74, 217 252, doi:10.1016/j.atmosres.2004.06.012, 2005.

Seity, Y., Brousseau, P., Malardel, S., Hello, G., Benard, P., Bouttier, F., Lac, C., and Masson, V.: The AROME-France ConvectiveScale Operational Model, Mon. Weather Rev., 139, 976-991, 2011.

Shaw, W. and Barnard, J.: Scales of turbulence decay from observations and direct numerical simulation, in: 15th Symposium on Boundary Layers and Turbulence, p. 8.3, Wageningen University, The Netherlands, 2002.

Sorbjan, Z.: Decay of convective turbulence revisited, Bound.-Lay. Meteorol., 82, 501-515, 1997.

Sullivan, P., Mc Williams, J., and Moeng, C.-H.: A subgrid-scale model for large-eddy simulation of planetary boundary-layer flows, Bound.-Lay. Meteorol., 71, 247-276, 1994.

Sullivan, P. P. and Patton, E. G.: The Effect of Mesh Resolution on Convective Boundary Layer Statistics and Structures Generated by Large-Eddy Simulation, J. Atmos. Sci., 68, 2395-2415, doi:10.1175/JAS-D-10-05010.1, 2011.

Taylor, A., Beare, R., and Thomson, D.: Simulating Dispersion in the Evening-Transition Boundary Layer, Bound.-Lay. Meteorol., 153, 389-407, doi:10.1007/s10546-014-9960-0, 2014.

Vilà-Guerau de Arellano, J., Dosio, A., Vinuesa, J.-F., Holtslag, A. A. M., and Galmarini, S.: The dispersion of chemically reactive species in the atmospheric boundary layer, Meteorol. Atmos. Phys., 87, 23-38, doi:10.1007/s00703-003-0059-2, 2004. 